\title{
Review
}

\section{Effectiveness of diabetes self-management education (DSME) in type 2 diabetes mellitus (T2DM) patients: Systematic literature review}

\author{
Ucik Ernawati, Titin Andri Wihastuti, Yulian Wiji Utami \\ School of Nursing, Faculty of Medicine, Universitas Brawijaya, Malang, Indonesia
}

\begin{abstract}
Diabetes mellitus is a chronic disease characterized by high glucose levels (hyperglycemia) due to metabolic disorders that prevent patients from producing sufficient amounts of insulin. This research aims to test the effectiveness of implementing diabetes self-management education in patients with Type 2 diabetes mellitus. The search for relevant articles was carried out through Google Scholar, PubMed, ProQuest, and Science Direct using the keywords diabetes mellitus, management education, self-care, diabetes self-management education, DSME, T2DM. The articles were then selected based on inclusion and exclusion criteria. Furthermore, the data were extracted, grouped, and concluded. Based on 15 articles, diabetes self-management education intervention provides significant effectiveness to lifestyle changes and the self-care of T2DM patients. In conclusion, diabetes self-management education intervention has been shown to be effective in dealing with type 2 diabetes mellitus. Furthermore, DSME has a positive effect on lifestyle changes and the self-care of T2DM patients.
\end{abstract}

\section{Introduction}

Diabetes mellitus (DM) is a chronic disease characterized by high glucose levels (hyperglycemia) due to metabolic disorders that prevent the patient from producing sufficient amounts of insulin. The disease can be prevented and controlled by engaging in certain behaviors and lifestyles such as regular exercise, healthy eating patterns, avoiding smoking, and controlling fat and glucose in the blood. ${ }^{1}$ The World Health Organization stated that the number of people living with diabetes mellitus (DM) worldwide reached 422 million, and every year 1.6 million deaths are recorded. ${ }^{2}$ The prevalence of the disease in the world is estimated to reach 642 million people by 2040. In 2019, the countries with the highest number of DM sufferers were China, India, the United States, Pakistan, Brazil, Mexico, and Indonesia, with an estimated number of 10 million patients. ${ }^{3}$ The number of people living with diabetes could be much greater than the prevalence described, because most sufferers only seek medical help after complications occur. The rising prevalence of diabetes mellitus is due to several factors, such as unhealthy behavior. ${ }^{1}$ This behavior is still rampart in Indonesian society, and is evidenced by the results of the Basic Health Research $2018,{ }^{1}$ where $13.6 \%$ of the residents were overweight, $21.8 \%$ had obesity, and $31 \%$ central obesity. Other unhealthy habits include the use of tobacco by men $(62.9 \%)$ and smoking by adolescents (10-18 years) $(23.91 \%) .{ }^{4}$ There are seven major behaviors related to diabetes self-care management, they include diet, physical activity, monitoring blood glucose levels, adherence to proper medication consumption, good problem solving, coping skills, and risk reduction behavior. ${ }^{5}$ Continuous selfcare will reduce the incidence of DM complications. However, most DM sufferers do not practice adequate self-care techniques such as controlling fasting blood glucose levels. ${ }^{6}$

DM management focuses on several aspects, namely education, meal planning, changes in lifestyle, physical activity, habits. ${ }^{7}$ One study explained that educational interventions influence knowledge, physical activity, food intake, self-efficacy, and health literacy. ${ }^{8}$ Diabetes self-management education (DSME) plays a key role in empowering people with diabetes to engage and sustain lifestyle changes, which have been shown to improve health outcomes. DSME is the process of facilitating the knowledge, attitudes, and abilities necessary for self-management. ${ }^{9}$ In addition to this, DSME play an important role in influencing the self-care practices of patients with diabetes mellitus. Based on this phenomenon, a literature review was prepared to highlight effectiveness of DSME on T2DM.

\section{Design and Methods \\ The collection and review of articles was carried during the month of October 2020. Furthermore, published articles were obtained through several electronic databases, such as Google Scholar, PubMed, ProQuest, and ScienceDirect using the key- words diabetes mellitus, self-care, diabetes self-management edu- cation, and DSME. The articles obtained from these databases were then selected based on the inclusion and exclusion criteria in}

Significance for public health

Globally, there are various pillars of diabetes mellitus management. One of the important pillars for the prevention and management is education. When properly carried out, it provides benefits to people with diabetes mellitus. Furthermore, the Association of Diabetes Care and Education (AADE) has guidelines for diabetes self-management education (DSME). In reality, there are many health workers that provide education without paying attention to these guidelines. Therefore, this study on the effectiveness of diabetes self-management education (DSME) would provide information regarding the importance of using these guidelines. 
order to obtain relevant articles. In addition to this, articles designs were selected using cross-sectional, randomized controlled trials (RCT), systematic reviews, and quasi-experimental studies. Subsequently, the data was then extracted, grouped, and concluded; 137 articles were obtained through the selection process (inclusion and exclusion criteria) (Table 1). These articles were then assessed for criticism and 15 were found to be relevant to the criteria.

\section{Results and discussions}

The effectiveness of DSME in T2DM is the main focus of this literature review. The heterogeneity of DSME implementation were seen based on the number of sessions, the time span, and the methods used. The study presented 6 articles with homogeneous results showing that DSME has a good effect on T2DM patients (Table 2).

Table 1. Inclusion and exclusion criteria.

Inclusion Axclusion

1. Research related to diabetes self-management education (DSME) or diabetes self-management education (DSME),

1. Publications in the form of news, quotes, abstracts, and editorial only.

DM management and self-care

2. Research provides information regarding the effects of DSME

2. Research does not contain all components of the journal

3. The full text is available in English or Indonesian

3. The text is not in English or Indonesian

4. Q1-Q3 qualified journal 4. Unqualified journals Q1-03

Table 2. Article review result.

No. Title

1 Participation in structured diabetes mellitus self-management education program and association with lifestyle behavior: results from a population-based study

Researcher (Year) Research purposes

Carmienke S, Baumert J, Whether participation in structured Gabrys L, et al. (2020) diabetes self-management education
(DSME) programs for participants with diabetes mellitus is associated with healthy lifestyles in routine care apart from randomized controlled studies remains unclear and is a question of this study.

2 Diabetes self-management education (DSME) - Effect on knowledge, self-care behavior, and self-efficacy among type 2 diabetes patients in Ethiopia: A controlled clinical trial
Hailu FB, Moen A, Diabetic patients must be equipped Hjortdahl P (2019) with the necessary knowledge to perform self-care activities according to confidence. Researchers prepared a diabetes self-management education (DSME) intervention and assessed how this influenced diabetes knowledge levels, self-care behavior, and self-reported patient self-efficacy.

3 Effect of diabetes self-management education on glycemic control among type 2 diabetic patients at a family medicine clinic in Kenya: A randomized controlled trial

4 The effect of diabetes self-management education on body weight, glycemic control, and other metabolic markers in patients with type 2 diabetes mellitus

5 Diabetes self-management education improves quality of care and clinical outcomes determined by a diabetes bundle measure

Gathu CW, Shabani J, This study seeks to assess the effectiveness Kunyiha N, Ratansi R (2018) of DSME and also compare the effects of

DSME by certified diabetes educators and family physicians.

Yuan C, Lai CW, Chan LW, To comprehensively evaluate the effect (DSME) Quasi-Experiment 76 participants et al. (2014) on metabolic markers and atherosclerotic parameters in patients with type 2 diabetes.

Brunisholz KD, Briot $\mathrm{P}, \quad$ This study aims to determine the impact of the Hamilton S, et al. (2014) DSME intervention by measuring HbAlc and diabetes bundle components so that diabetes care can be improved.

6 The effect of diabetes self-management education on Hbalc level and fasting blood sugar in type 2 diabetes mellitus patients in primary health care in Binjai City of North Sumatera, Indonesia

7 Diabetes self-management education and medical nutrition therapy: a multisite study documenting the efficacy of registered dietitian nutritionist interventions in the management of glycemic control and diabetic dyslipidemia through retrospective chart review

8 Effect of diabetes self-management education (DSME) on glycated hemoglobin (HbAlc) level among patients with T2DM: Systematic review and meta-analysis of randomized controlled trials

\section{Design}

Cross-sectional population-based analysis

Quasi-Experiment $\quad 220$ participants

To evaluate HbAlc levels and fasting blood sugar in T2DM patients after the DSME intervention was carried out in Binjai City, North Sumatra, Indonesia.

Document outcomes for patients with type 2 diabetes(T2D) completing DSME and MNT through American Diabetes Association-recognized programs.

RCT

96 participants

\section{5 participants}


Table 2. Continued from previous page.

\begin{tabular}{|c|c|c|c|c|c|}
\hline \multicolumn{2}{|c|}{ №. Title } & \multirow{2}{*}{$\begin{array}{l}\text { Researcher (Year) } \\
\text { Qayyum AA, Lone SW, } \\
\text { Ibrahim MN, et al. (2010) }\end{array}$} & \multirow{2}{*}{$\begin{array}{l}\text { Research purposes } \\
\text { To evaluate the effect of diabetes self-management } \\
\text { education (DSME) on glycemic control (HbAlc) } \\
\text { in Pakistani children suffering from type-1 } \\
\text { diabetes mellitus. }\end{array}$} & \multirow{2}{*}{$\begin{array}{l}\text { Desiggn } \\
\text { Quasi-experiment }\end{array}$} & \multirow{2}{*}{$\begin{array}{l}\text { Sample } \\
50 \text { participants }\end{array}$} \\
\hline 9 & $\begin{array}{l}\text { Effects of diabetes self-management education } \\
\text { on glycaemic control in children with } \\
\text { insulin-dependent diabetes mellitus. }\end{array}$ & & & & \\
\hline 10 & $\begin{array}{l}\text { Effectiveness of diabetes self-management } \\
\text { education on quality of life in diabetic } \\
\text { elderly females }\end{array}$ & $\begin{array}{l}\text { Kargar Jahromi M, } \\
\text { Ramezanli S, Taheri L. } \\
\text { (2014) }\end{array}$ & $\begin{array}{l}\text { The aim of the present study was to determine } \\
\text { the effectiveness of diabetes self-management } \\
\text { education on quality of life in elderly females with } \\
\text { diabetic mellitus (type 2) in Shiraz, Iran, 2013. }\end{array}$ & Quasi-experiment & 90 participants \\
\hline 11 & $\begin{array}{l}\text { The effect of self-management education } \\
\text { through weblogs on the quality of life } \\
\text { of diabetic patients }\end{array}$ & $\begin{array}{l}\text { Rasoul AM, Jalali R, } \\
\text { Abdi A, Salari N, et al. } \\
\text { (2019) }\end{array}$ & $\begin{array}{l}\text { The aim of determining the effect of self-management } \\
\text { education through weblogs on the quality } \\
\text { of life of affect the patients. }\end{array}$ & Quasi-experiment & 98 participants \\
\hline 12 & $\begin{array}{l}\text { DM-calendar app as a diabetes self-management } \\
\text { education on adult type } 2 \text { diabetes mellitus: } \\
\text { a randomized controlled trial }\end{array}$ & $\begin{array}{l}\text { Kusnanto, Widyanata KAJ, } \\
\text { Suprajitno, Arifin H (2019) }\end{array}$ & $\begin{array}{l}\text { The aim was to evaluate the effect of diabetes } \\
\text { mellitus calendar app as a Diabetes Self-Management } \\
\text { Education (DSME) program on self-efficacy, } \\
\text { HbAlc levels, lipid profile, and insulin in adult type } \\
2 \text { diabetes mellitus (T2DM). }\end{array}$ & $\begin{array}{l}\text { Randomized } \\
\text { controlled trial }\end{array}$ & 30 participants \\
\hline 13 & $\begin{array}{l}\text { Effect of a nurse-led diabetes self-management } \\
\text { education program on glycosylated hemoglobin } \\
\text { among adults with type } 2 \text { diabetes }\end{array}$ & $\begin{array}{l}\text { Azami G, Soh KL, Sazlina SG, } \\
\text { Salmiah MS, et al. (2018) }\end{array}$ & $\begin{array}{l}\text { The aim of this study was to investigate the effectiveness } \\
\text { of a nurse-led diabetes self-management education } \\
\text { on glycosylated hemoglobin. }\end{array}$ & Quasi-Experiment & 71 participants \\
\hline 14 & $\begin{array}{l}\text { Effects of an outpatient diabetes self-management } \\
\text { education on patients with type } 2 \text { diabetes in China: } \\
\text { A randomized controlled trial }\end{array}$ & $\begin{array}{l}\text { Zheng F, Liu S, Liu Y, } \\
\text { Deng L (2019) }\end{array}$ & $\begin{array}{l}\text { This study is aimed at assessing the effectiveness of a } \\
\text { simple outpatient diabetes self-management } \\
\text { education program. }\end{array}$ & $\begin{array}{l}\text { Randomized } \\
\text { controlled trial }\end{array}$ & 60 participants \\
\hline 15 & $\begin{array}{l}\text { Effect of a community-based diabetes } \\
\text { self-management empowerment program } \\
\text { on mental health-related quality of life: } \\
\text { a causal mediation analysis from a randomized } \\
\text { controlled trial }\end{array}$ & $\begin{array}{l}\text { Sugiyama T, Steers WN, } \\
\text { Wenger NS, et al. (2015) }\end{array}$ & $\begin{array}{l}\text { The aim of this systematic review and meta-analysis } \\
\text { is to investigate the association between DSME or support } \\
\text { (DSME/S) and glycemic control among T2DM patients. }\end{array}$ & $\begin{array}{l}\text { Randomized } \\
\text { controlled trial }\end{array}$ & 516 participants \\
\hline
\end{tabular}

The DSME intervention given to T2DM patients in Ethiopia had a positive impact, such as an increase in knowledge and adherence to diet therapy, exercise, glucose monitoring, and wound care. ${ }^{10}$ In line with that, another study explained that DSME significantly improved medication adherence, self-management behavior, knowledge, self-efficacy, and quality of life. ${ }^{11-13}$ Several studies show that DSME interventions improve the quality of life. ${ }^{14-17}$ Through these interventions, bad behavior such as smoking and alcohol consumption can also be avoided or reduced. ${ }^{10}$

Several interventions are also able to influence lifestyle changes such as increasing the duration of exercises (cycling, walking, aerobics), reducing smoking habits, and increasing the consumption of fruits and vegetables. ${ }^{18}$ Lifestyle changes caused by DSME interventions are expected to improve the clinical and health status of T2DM patients. One study proved this showing DSME's effectiveness in controlling fasting blood glucose, random blood glucose, total cholesterol, and triglycerides. ${ }^{11}$ In line with that, other studies also showed that DSME can influence glycemic control, body weight and BMI control. ${ }^{11,19-21}$ Apart from data homogeneity in the article, another difference was found regarding the effect of DSME on HbA1c. Cunningham ${ }^{14}$ states that DSME does not significantly affect HbA1c. This is in contrast with other studies which explain that this intervention can significantly affect HbA1c. ${ }^{21-26}$ After reviewing several studies, it is proven that DSME has a positive effect on the lifestyle and clinical or health status of T2DM patients. However, the implementation process could be influenced by several factors, namely: i) limited resources, ii) culture, iii) relationship with diabetes, and iv) rela- tionship with clinic.

This systematic review focuses on the effectiveness of DSME on T2DM disease progression. It is known that the DSME intervention provides benefits to the development of T2DM disease. The demonstrated benefits point to efforts to increase T2DM development through lifestyle changes and self-care for T2DM patients. Lifestyle changes such as exercising diligently, increasing consumption of fruits and vegetables, and avoiding smoking can improve the patient's clinical condition and the patient's health status. ${ }^{18}$ The clinical condition can be seen from the levels of blood glucose and HbAlc.

DSME has a positive effect on T2DM patients to improve their knowledge, behavior, self-efficacy, and clinical conditions of patients such as blood glucose levels, HbA1c, lipid profiles. ${ }^{10,11,19-}$ ${ }^{21}$ However, there were differences in results in studies involving HbAlc levels. The difference that lies in the presence or absence of this effect on $\mathrm{HbAlc}$ can be a concern in future studies to consider the determining factors that can influence it. Several studies in this review show that the effectiveness of DSME is influenced by education providers and support systems. ${ }^{17,22,25,26}$

\section{Conclusions}

Based on the 15 articles reviewed, it was found that DSME intervention provides significant effectiveness to lifestyle changes and the self-care of T2DM patients. Therefore, it improves the clinical or health status of T2DM patients. 
Correspondence: Ucik Ernawati, School of Nursing, Faculty of Medicine, Universitas Brawijaya, Jl. Puncak Dieng, Kunci, Kalisongo, Kec. Dau, Malang, East Java 65151, Indonesia.

Tel. +62.341569117 - Fax: +62.341564755.

E-mail: ucikerna@student.ub.ac.id

Key words: Diabetes mellitus; management education; self-care; diabetes self-management education.

Acknowledgment: The authors are grateful to the co-authors and reviewers for this research.

Contributions: UE, conception, design, acquisition of data, interpretation of results and final write-up of this manuscript; TAW, YWU, supervised the author's masters' research project and reviewed the manuscript for publication.

Conflict of interest: The authors declare no potential conflict of interest.

Funding: This research received no specific grant from any funding agency in the public, commercial, or not-for-profit sectors.

Ethical Approval: Not applicable.

Conference presentation: Part of this study was presented at the $1^{\text {st }}$ International Nursing and Health Sciences Symposium, November $13^{\text {th }}$ to $15^{\text {th }} 2020$, Brawijaya University, Malang, Indonesia.

Received for publication: 16 January 2021.

Accepted for publication: 24 March 2021.

o Copyright: the Author(s), 2021

Licensee PAGEPress, Italy

Journal of Public Health Research 2021;10:2240

doi:10.4081/jphr.2021.2240

This work is licensed under a Creative Commons Attribution NonCommercial 4.0 License (CC BY-NC 4.0).

\section{References}

1. Ministry of Health Republic of Indonesia. Basic Health Research 2018. Jakarta: Ministry of Health Republic of Indonesia; 2018.

2. WHO. World health statistics 2018: monitoring health for the SDGs. Geneva: WHO; 2018.

3. Sasmiyanto S. [Faktor Presdiposisi Perilaku Kesehatan Penderita Diabetes Mellitus Tipe 2 (Predisposition factors of health behavior of type 2 diabetes mellitus patients)].[Article in Indonesian]. J Keperawatan Silampari 2020;3:466-76.

4. American Association of Diabetes Educators. An effective model of diabetes care and education: Revising the AADE7 Self-Care Behaviors ${ }^{\circledR}$. Diabetes Educ 2020;46:139-60.

5. Lee SK, Shin DH, Kim YH, et al. Effect of diabetes education through pattern management on self-care and self-efficacy in patients with type 2 diabetes. Int J Environ Res Public Health 2019;16:3323.

6. Ramadhani S, Fidiawan A, Andayani TM, et al. Pengaruh SelfCare terhadap Kadar Glukosa Darah Puasa Pasien Diabetes Melitus Tipe-2 (Effect of self-care on fasting blood glucose levels in type-2 diabetes mellitus patients)].[Article in Indonesian]. Jurnal Manajemen Dan Pelayanan Farmasi 2019;9:118-25
7. Aschner P. New IDF clinical practice recommendations for managing type 2 diabetes in primary care. Diabetes Res Clin Pract 2017;132:169-70.

8. Ghisi GLM, Aultman C, Konidis R, et al. Effectiveness of an education intervention associated with an exercise program in improving disease-related knowledge and health behaviours among diabetes patients. Patient Educ Couns 2020;103:17907.

9. Fan L, Sidani S. Factors influencing preferences of adults with type 2 diabetes for diabetes self-management education interventions. Can J Diabetes 2018;42:645-51.

10. Hailu FB, Moen A, Hjortdahl P. Diabetes self-management education (DSME) - Effect on knowledge, self-care behavior, and self-efficacy among type 2 diabetes patients in Ethiopia: A controlled clinical trial. Diabetes Metab Syndr Obes 2019; $12: 2489$.

11. Mikhael EM, Hassali MA, Hussain SA. Effectiveness of diabetes self-management educational programs for type 2 diabetes mellitus patients in middle east countries: A systematic review. Diabetes Metab Syndr Obes 2020;13:117.

12. Kusnanto, Widyanata KAJ, Suprajitno, et al. DM-calendar app as a diabetes self-management education on adult type 2 diabetes mellitus: a randomized controlled trial. J Diabetes Metab Disord 2019;18:557-63.

13. Azami G, Soh KL, Sazlina SG, et al. Effect of a nurse-led diabetes self-management education program on glycosylated hemoglobin among adults with type 2 diabetes. J Diabetes Res 2018;2018:1-12.

14. Cunningham AT, Crittendon DR, White N, et al. The effect of diabetes self-management education on $\mathrm{HbAlc}$ and quality of life in African-Americans: A systematic review and meta-analysis. BMC Health Serv Res 2018;18:1-13.

15. Jahromi MK, Ramezanli S, Taheri L. Effectiveness of diabetes self-management education on quality of life in diabetic elderly females. Glob J Health Sci 2015;7:10.

16. Rasoul AM, Jalali R, Abdi A, et al. The effect of self-management education through weblogs on the quality of life of diabetic patients. BMC Med Inform Decis Mak 2019;19:1-12.

17. Sugiyama T, Steers WN, Wenger NS, et al. Effect of a community-based diabetes self-management empowerment program on mental health-related quality of life: A causal mediation analysis from a randomized controlled trial. BMC Health Serv Res 2015;15:1-9.

18. Carmienke S, Baumert J, Gabrys L, et al. Participation in structured diabetes mellitus self-management education program and association with lifestyle behavior: Results from a population-based study. BMJ Open Diabetes Res Care 2020;8:e01066.

19. Yuan C, Lai CWK, Chan LWC, et al. The effect of diabetes self-management education on body weight, glycemic control, and other metabolic markers in patients with type 2 diabetes mellitus. J Diabetes Res 2014;2014:1-6.

20. Marincic PZ, Salazar MV, Hardin A, et al. Diabetes self-management education and medical nutrition therapy: A multisite study documenting the efficacy of registered dietitian nutritionist interventions in the management of glycemic control and diabetic dyslipidemia through retrospective chart rev. J Acad Nutr Diet 2019;119:449-63.

21. Zheng F, Liu S, Liu Y, et al. Effects of an outpatient diabetes self-management education on patients with type 2 diabetes in China: A randomized controlled trial. J Diabetes Res 2019;2019:1073131.

22. Gathu CW, Shabani J, Kunyiha N, et al. Effect of diabetes selfmanagement education on glycaemic control among type 2 
diabetic patients at a family medicine clinic in Kenya: A randomised controlled trial. African J Prim Heal Care Fam Med 2018;10:1-9.

23. Brunisholz KD, Briot P, Hamilton S, et al. Diabetes self-management education improves quality of care and clinical outcomes determined by a diabetes bundle measure. J Multidiscip Healthc 2014;7:533.

24. Rusdiana, Savira M, Amelia R. The effect of diabetes selfmanagement education on Hbalc level and fasting blood sugar in type 2 diabetes mellitus patients in primary health care in Binjai city of north Sumatera, Indonesia. Open Access Maced
J Med Sci 2018;6:715.

25. Bekele BB, Negash S, Bogale B, et al. Effect of diabetes selfmanagement education (DSME) on glycated hemoglobin (HbA1c) level among patients with T2DM: Systematic review and meta-analysis of randomized controlled trials. Diabetes Metab Syndr Clin Res Rev 2020;15:177-85.

26. Qayyum AA, Lone SW, Ibrahim MN, et al. Effects of diabetes self-management education on glycaemic control in children with insulin-dependent diabetes mellitus. J Coll Physicians Surg Pakistan 2010;20:802-5. 